\title{
Acute kidney injury in a tropical country: a cohort study of 253 patients in an infectious diseases intensive care unit
}

\author{
Elizabeth De Fransceco Daher ${ }^{[1]}$, Geraldo Bezerra da Silva Junior ${ }^{[1],[2],}$ \\ Ana Patrícia Freitas Vieira ${ }^{[1]}$, Juliana Bonfim de Souza ${ }^{[1]}$, Felipe dos Santos Falcão ${ }^{[1]}$, \\ Cristiane Rocha da Costa ${ }^{[1]}$, Anna Allicy Câmara da Silva Fernandes ${ }^{[1]}$ \\ and Rafael Siqueira Athayde Lima ${ }^{[1]}$
}

[1]. Departamento de Medicina Interna, Faculdade de Medicina, Universidade Federal do Ceará, Fortaleza, CE. [2]. Faculdade de Medicina, Mestrado em Saúde Coletiva, Centro de Ciências da Saúde, Universidade de Fortaleza, Fortaleza, CE.

\begin{abstract}
Introduction: Acute kidney injury (AKI) is a frequent and potentially fatal complication in infectious diseases. The aim of this study was to investigate the clinical aspects of AKI associated with infectious diseases and the factors associated with mortality. Methods: This retrospective study was conducted in patients with AKI who were admitted to the intensive care unit (ICU) of a tertiary infectious diseases hospital from January 2003 to January 2012. The major underlying diseases and clinical and laboratory findings were evaluated. Results: A total of 253 cases were included. The mean age was $46 \pm 16$ years, and $72 \%$ of the patients were male. The main diseases were human immunodeficiency virus (HIV) infection, HIV/acquired immunodeficiency syndrome (AIDS) (30\%), tuberculosis (12\%), leptospirosis (11\%) and dengue (4\%). Dialysis was performed in 70 cases $(27.6 \%)$. The patients were classified as risk $(4.4 \%)$, injury $(63.6 \%)$ or failure $(32 \%)$. The time between AKI diagnosis and dialysis was $3.6 \pm 4.7$ days. Oliguria was observed in 112 cases (45.7\%). The Acute Physiology and Chronic Health Evaluation (APACHE) II scores were higher in patients with HIV/AIDS $(57 \pm 20$, p-value $=0.01)$ and dengue $(68 \pm 11$, $p$-value $=0.01)$. Death occurred in 159 cases $(62.8 \%)$. Mortality was higher in patients with HIV/AIDS (76.6\%, p-value=0.02). A multivariate analysis identified the following independent risk factors for death: oliguria, metabolic acidosis, sepsis, hypovolemia, the need for vasoactive drugs, the need for mechanical ventilation and the APACHE II score. Conclusions: AKI is a common complication in infectious diseases, with high mortality. Mortality was higher in patients with HIV/AIDS, most likely due to the severity of immunosuppression and opportunistic diseases.
\end{abstract}

Keywords: Acute kidney injury. Intensive care unit. Infectious diseases. RIFLE criteria.

\section{INTRODUCTION}

The incidence of acute kidney injury (AKI) in hospitalized patients is approximately $5 \%$. This incidence is higher in the intensive care unit (ICU) and is accompanied by high mortality, especially when there is a need for dialysis, with indices ranging from $37-88 \%{ }^{1}$. AKI is a common complication in critical illness, which is associated with high mortality and has a separate independent effect on the risk of death ${ }^{1}$.

As the presence of infection is a risk factor for the development of AKI, this study highlights the roles of infectious diseases in kidney injury. Few studies have investigated the prognostic factors in infectious disease-associated $\mathrm{AKI}^{2,3}$. The

\footnotetext{
Address to: Elizabeth De Francesco Daher. Rua Vicente Linhares 1198, 60135-270 Fortaleza, CE, Brasil.

Phone: 5585 3224-9725; Fax: 5585 3261-3777

e-mail: ef.daher@uol.com.br; geraldobezerrajr@yahoo.com.br

Received 1 November 2013

Accepted 30 January 2014
}

aim of this study was to investigate the clinical aspects of AKI associated with infectious diseases and the factors associated with mortality using medical record review.

\section{METHODS}

The study was conducted at a tertiary infectious diseases hospital. The records of all patients admitted to the ICU from October 2003 to January 2012 were retrospectively evaluated. All patients who developed AKI during their ICU stay were included in the study. The study protocol was approved by the ethical committee of the institution.

The patients were classified according to the RIFLE criteria ("risk", "injury", "failure", "loss" and "end-stage renal disease") 4 . The baseline creatinine level was measured at the moment of hospital admission, or the lowest creatinine level before admission was considered. The RIFLE criteria were considered based on the highest creatinine level achieved by each patient during the hospital stay. The Acute Physiology and Chronic Health Evaluation (APACHE) II was used as the 
gold-standard severity score 5 . Oliguria was defined as urinary volume $<400 \mathrm{~mL} /$ day, despite appropriate fluid replacement.

The patients were divided into two groups, survivors and non-survivors, to investigate whether there were differences in the studied parameters. Non-survivors were included when death occurred after ICU discharge but before hospital discharge.

Statistical analyses were performed using SPSS 17.0 for Windows (SPSS Inc., Chicago, IL, USA) and consisted of univariate and multivariate analyses. Comparisons between the two groups of patients were performed using Student's t test, Fisher's exact test, the Mann-Whitney test and the Chisquare test, when appropriate. A logistic regression model was built for quantitative variables, and association measures were calculated (adjusted relative risk), with a confidence interval of $95 \%$. Multiple logistic regression analysis was used to identify the independent variables used as indicators of the predictors of mortality (dependent variable). In the analyses, $p$-values below $5 \%$ (p-value $<0.05)$ were considered statistically significant.

\section{RESULTS}

A total of 253 cases of AKI were recorded, with a mean age of $46 \pm 16$ years; $72 \%$ of the patients were male. The main diseases were human immunodeficiency virus (HIV)/acquired immunodeficiency syndrome (AIDS) (30\%), tuberculosis $(12 \%)$, leptospirosis $(11 \%)$, meningitis $(7.5 \%)$, leishmaniasis $(4.5 \%)$ and dengue ( $4 \%)$, as summarized in Table 1 . The patients were classified as risk (4.4\%), injury (63.6\%) or failure $(32 \%)$. The time between the diagnosis of AKI and dialysis was $3.6 \pm 4.7$ days. Oliguria was observed in 112 cases (45.7\%). Dialysis was performed in $70(27.6 \%)$ cases. The laboratory findings at ICU admission are shown in Table 2.
TABLE 1 - General data on critically ill patients with infectious disease-associated acute kidney injury.

\begin{tabular}{|c|c|c|}
\hline Parameter & \multicolumn{2}{|c|}{ Patients } \\
\hline Age (years)* & \multicolumn{2}{|c|}{$46 \pm 16$} \\
\hline \multicolumn{3}{|l|}{ Gender** } \\
\hline male & 181 & 72.0 \\
\hline female & 72 & 28.0 \\
\hline \multicolumn{3}{|l|}{ Primary diagnosis at admission** } \\
\hline HIV/AIDS & 77 & 30.0 \\
\hline tuberculosis & 31 & 12.0 \\
\hline leptospirosis & 28 & 11.0 \\
\hline sepsis & 28 & 11.0 \\
\hline meningitis & 19 & 7.5 \\
\hline tetanus & 14 & 5.5 \\
\hline pneumonia & 12 & 5.0 \\
\hline visceral leishmaniasis & 11 & 4.5 \\
\hline dengue & 10 & 4.0 \\
\hline viral hepatitis & 10 & 4.0 \\
\hline central nervous system infection & 10 & 4.0 \\
\hline urinary tract infection & 3 & 1.5 \\
\hline Time to develop AKI (days after admission)* & \multicolumn{2}{|c|}{$2.8 \pm 7.6$} \\
\hline Time to start dialysis (days)* & \multicolumn{2}{|c|}{$3.6 \pm 4.7$} \\
\hline Dialysis** & 70 & 27.6 \\
\hline
\end{tabular}

TABLE 2 - Laboratory findings for critically ill patients with infectious disease-associated acute kidney injury.

\begin{tabular}{|c|c|c|c|c|}
\hline Parameter & General $(n=253)$ & Survivors $(n=94)$ & Non-survivors $(n=159)$ & p-value \\
\hline Hematocrit (\%) & $30 \pm 7.9$ & $30 \pm 8.4$ & $30 \pm 8.9$ & 1.0 \\
\hline Platelets $\left(/ \mathrm{mm}^{3}\right)$ & $131,488 \pm 111,706$ & $145,838 \pm 113,038$ & $125,724 \pm 111,601$ & 0.16 \\
\hline Leukocytes $\left(/ \mathrm{mm}^{3}\right)$ & $11,964 \pm 10,529$ & $10429 \pm 5736$ & $11767 \pm 7051$ & 0.12 \\
\hline Serum urea (mg/dL) & $105 \pm 68$ & $108 \pm 62.15$ & $104 \pm 73.5$ & 0.65 \\
\hline Serum sodium $(\mathrm{mEq} / \mathrm{L})$ & $136 \pm 10$ & $135 \pm 8.5$ & $136 \pm 11$ & 0.44 \\
\hline Serum potassium $(\mathrm{mEq} / \mathrm{L})$ & $4.4 \pm 2.5$ & $4.5 \pm 4.07$ & $4.4 \pm 1.14$ & 0.76 \\
\hline Blood pH & $7.29 \pm 0.13$ & $7.36 \pm 0.10$ & $7.25 \pm 0.13$ & $<0.01$ \\
\hline
\end{tabular}

AST: aspartate aminotransferase; ALT: alanine transaminase; The values are expressed as the means \pm SDs. Comparison of survivors vs. nonsurvivors. Student's t test. 
TABLE 3 - Characteristics of critically ill patients with infectious disease-associated acute kidney injury.

\begin{tabular}{|c|c|c|c|c|c|c|c|}
\hline$\frac{\text { Parameter }}{\text { Anemia }}$ & \multicolumn{2}{|c|}{ General $(n=253)$} & \multicolumn{2}{|c|}{ Survivors $(\mathrm{n}=94)$} & \multicolumn{2}{|c|}{ Non-survivors $(\mathrm{n}=159)$} & $\frac{\mathrm{p} \text {-value }}{0.14}$ \\
\hline Need for MV & 155 & 63.5 & 38 & 24.5 & 117 & 75.5 & $<0.01$ \\
\hline Sepsis & 152 & 62.3 & 35 & 23.0 & 117 & 77.0 & $<0.01$ \\
\hline Low platelet count & 152 & 62.3 & 50 & 32.9 & 102 & 67.1 & 0.11 \\
\hline Hepatopathy & 97 & 43.1 & 28 & 28.9 & 69 & 71.1 & 0.03 \\
\hline Hypotension & 67 & 27.1 & 16 & 23.9 & 51 & 76.1 & 0.02 \\
\hline Hyperkalemia & 45 & 18.5 & 11 & 24.4 & 34 & 75.6 & 0.06 \\
\hline
\end{tabular}

MV: mechanical ventilation. The values are expressed as the means \pm SDs. Comparison of survivors vs. non-survivors. Fisher's exact test.

TABLE 4 - Mortality in critically ill patients with infectious disease-associated acute kidney injury according to the RIFLE criteria.

\begin{tabular}{lrrrrr}
\hline RIFLE criteria & General $(\mathrm{n}=253)$ & \multicolumn{2}{c}{ Survivors (n=94) } & Non-survivors $(\mathrm{n}=159)$ \\
\hline Risk & 11 & 4.4 & 5 & 44.4 & 6 \\
Injury & 161 & 63.6 & 53 & 32.9 & 108 \\
Failure & 81 & 32.0 & 33 & 40.7 & 48.1 \\
\hline
\end{tabular}

The values are expressed as relative frequencies. Comparison of survivors vs. non-survivors. Chi-square test. $\mathrm{p}$-value $=0.33$.

TABLE 5 - Risk factors for death in critically ill patients with infectious disease-associated acute kidney.

\begin{tabular}{lcc}
\hline Parameter & RR & $95 \% \mathrm{CI}$ \\
\hline Metabolic acidosis & 4.9 & $2.7-8.7$ \\
Sepsis & 4.3 & $2.4-7.6$ \\
Need for MV & 3.7 & $2.1-6.5$ \\
Hyperkalemia & 3.0 & $1.5-6.0$ \\
Hypotension & 2.1 & $1.1-4.0$ \\
Use of vasoactive drugs & 6.7 & $3.7-11.9$ \\
\hline
\end{tabular}

MV: mechanical ventilation; RR: relative risk. CI: confidence interval. The values are expressed as the means \pm SDs.

The comparison of survivors and non-survivors revealed higher frequencies of mechanical ventilation, sepsis and hypotension among the non-survivors, as shown in Table 3.

The mean APACHE II score was $50 \pm 22$. The scores were higher in patients with HIV/AIDS $(57 \pm 20$, p-value $=0.01)$ and dengue $(68 \pm 11, \mathrm{p}$-value $=0.01)$ and were lower in patients with tuberculosis $(33 \pm 19, p$-value $=0.0001)$ and leptospirosis $(34 \pm 18$, $\mathrm{p}$-value $=0.0002)$ compared with the total sample score.

The distribution of survivors and non-survivors according to the RIFLE criteria was as follows: Risk ( $44.4 \%$ vs. $54.6 \%$, p-value $=0.31)$, Injury $(32.9 \%$ vs. $67.1 \%$, p-value $=1.66)$ and Failure $(40.7 \%$ vs. $59.2 \%$, p-value $=1.20)$ (Table 4$)$.

Death occurred in 159 cases $(62.8 \%)$. Mortality was higher in patients with HIV/AIDS $(76.6 \%$, $\mathrm{p}$-value $=0.02)$ and was lowest in those with leptospirosis $(28.5 \%$, p-value $=0.0009)$. The risk factors for death are described in Table $\mathbf{5}$.

\section{DISCUSSION}

AKI is a common complication in critically ill patients and is associated with substantial increases in morbidity and mortality. The course of many infectious diseases can be complicated by AKI, as demonstrated in this study.

In this study, the mean age was 46 years, and $72 \%$ of the patients were male. Males have consistently predominated in reports on the incidence of AKI as a complication in infections, such as HIV ${ }^{6,7}$, leptospirosis ${ }^{8}$ and other community-acquired AKI. The reasons for such gender differences are unclear but are likely associated with work activities.

The cause of AKI in the ICU is commonly multifactorial; it frequently develops from a combination of hypovolemia, sepsis, medications and hemodynamic perturbations ${ }^{9}$. Sepsis is the most common cause of AKI in the general ICU, accounting for up to $50 \%$ of cases $^{10}$. Silva Jr et al. ${ }^{7}$ detected AKI in $37 \%$ of 532 HIV/AIDS patients. In the present study, the main causes of ICU admission were HIV/AIDS (30\%), tuberculosis (12\%) and leptospirosis (11\%). 
There are few prospective data regarding the appropriate timing of the initiation of dialysis; thus, the question of appropriate timing remains unanswered and controversial ${ }^{11-13}$. In the literature, the need for dialysis in patients with leptospirosis varies from $16-40 \%{ }^{14,15}$. In the present study, dialysis was performed in $27 \%$ of cases, and the length of time between AKI diagnosis and the start of dialysis was 3 days.

The RIFLE criteria were independently associated with hospital mortality in a multivariable analysis ${ }^{7,16,17}$. However, in our study, the RIFLE criteria were not an independent predictor of mortality. This fact may have been due to the specific systemic conditions in infectious diseases that override renal lesions in determining mortality.

Multiple studies of patients with AKI and sepsis ${ }^{18,19}$ and mechanical ventilation ${ }^{20,21}$ have consistently demonstrated the increased risk of death. Mortality among HIV patients varies from approximately $25-70 \%$ and is significantly higher among patients with $\mathrm{AKI}^{7,22}$. Choi et al. ${ }^{23}$ reported $48 \%$ mortality in HIV-infected patients with an estimated glomerular filtration rate (eGFR) of less than 60 and albuminuria. In the present study, $63 \%$ of the patients died. Mortality was higher in patients with HIV/AIDS. The risk factors for death in the present study were metabolic acidosis, sepsis, the need for mechanical ventilation, hypotension, hyperkalemia and the use of vasoactive drugs, similar to the findings of previous studies ${ }^{2,7,24}$.

In summary, AKI is a common complication in infectious diseases, with high mortality. Dialysis was instituted in few cases (27\%) and was started late when it was employed. Mortality was higher in patients with HIV/AIDS, most likely due to the severity of immunosuppression and opportunistic diseases. Better knowledge of the factors associated with bad prognoses in ARF cases is important for improving prevention and treatment, especially among critically ill patients.

\section{CONFLICT OF INTEREST}

The authors declare that there is no conflict of interest.

\section{FINANCIAL SUPPORT}

\section{Brazilian Research Council (CNPq).}

\section{REFERENCES}

1. Bellomo R, Ronco C, Kellum JA, Mehta RL, Palevsky P, Acute Dialysis Quality Initiative workgroup. Acute renal failure - definition, outcome measures, animal models, fluid therapy and information technology needs: the Second International Consensus Conference of the Acute Dialysis Quality Initiative (ADQI) Group. Crit Care 2004; 8:R204-R212.

2. Daher EF, Marques CN, Lima RS, Silva Junior GB, Barbosa AS, Barbosa ES, et al. Acute kidney injury in an infectious disease intensive care unit - an assessment of prognostic factors. Swiss Med Wkly 2008; 138:128-133.

3. Basu G, Chrispal A, Boorugu H, Gopinath KG, Chandy S, Prakash JA, et al. Acute kidney injury in tropical acute febrile illness in a tertiary care centre - RIFLE criteria validation. Nephrol Dial Transplant 2011; 26: 524-531.
4. Ricci Z, Cruz D, Ronco C. The RIFLE criteria and mortality in acute kidney injury: a systematic review. Kidney Int 2008; 73:538-546.

5. Knaus WA, Draper EA, Wagner DP, Zimmerman JE. APACHE II: a severity of disease classification system. Crit Care Med 1985; 13:818-829.

6. Cohen SD, Chawla LS, Kimmel PL. Acute kidney injury in patients with human immunodeficiency virus infection. Curr Opin Crit Care 2008; 14:647-653.

7. Silva Junior GB, Libório AB, Mota RM, Abreu KL, Silva AE, Araújo SM, et al. Acute kidney injury in AIDS: frequency, RIFLE classification and outcome. Braz J Med Biol Res 2010; 43:1102-1108.

8. Ittyachen AM, Krishnapillai TV, Nair MC, Rajan AR. Retrospective study of severe cases of leptospirosis admitted in the intensive care unit. J Postgrad Med 2007; 53:232-235.

9. Dennen P, Douglas IS, Anderson R. Acute kidney injury in the intensive care unit: an update and primer for the intensivist. Crit Care Med 2010; $38: 261-275$.

10. Hoste EA, Clermont G, Kersten A, Kersten A, Venkataraman R, Angus DC, et al. RIFLE criteria for acute kidney injury are associated with hospital mortality in critically ill patients: A cohort analysis. Crit Care 2006; $10:$ R73

11. Bagshaw SM, Uchino S, Bellomo R, Morimatsu H, Morgera S, Schetz M, et al. Timing of renal replacement therapy and clinical outcomes in critically ill patients with severe acute kidney injury. J Crit Care 2009; 24:129-140

12. Beddhu S, Samore MH, Roberts MS, Stoddard GJ, Ramkumar N, Pappas LM, et al. Impact of timing of initiation of dialysis on mortality. J Am Soc Nephrol 2003; 14:2305-2312.

13. Liu KD, Himmelfarb J, Paganini E, Ikizler TA, Soroko SH, Mehta RL, et al. Timing of initiation of dialysis in critically ill patients with acute kidney injury. Clin J Am Soc Nephrol 2006; 1:915-919.

14. Cetin BD, Harmankaya O, Hasman H, Gunduz A, Oktar M, Seber E. Acute renal failure: a common manifestation of leptospirosis. Ren Fail 2004; 26:655-661.

15. Hurst FP, Neff RT, Katz AR, Buchholz AE, Sasaki DM, Berg BW, et al. Acute kidney injury requiring hemodialysis in patients with anicteric leptospirosis. Clin Nephrol 2009; 72:186-192.

16. Uchino S, Kellum JA, Bellomo R, Doig GS, Morimatsu H, Morgera S, et al. Acute renal failure in critically ill patients: A multinational, multicenter study. JAMA 2005; 294:813-818.

17. Bagshaw SM, George C, Bellomo R, ANZICS Database Management Committe. A comparison of the RIFLE and AKIN criteria for acute kidney injury in critically ill patients. Nephrol Dial Transplant 2008; 23:1569-1574.

18. Bagshaw SM, Uchino S, Bellomo R, Morimatsu H, Morgera S, Schetz M, et al. Septic acute kidney injury in critically ill patients: Clinical characteristics and outcomes. Clin J Am Soc Nephrol 2007; 2:431-439.

19. Lima RS, Marques CN, Silva Junior GB, Barbosa AS, Barbosa ES, Mota RM, et al. Comparison between early and delayed acute kidney injury secondary to infectious disease in the intensive care unit. Int Urol Nephrol 2008; 40:731-739.

20. Vincent JL, Mendonca A, Cantraine F, Moreno R, Takala J, Suter PM, et al. Use of the SOFA score to assess the incidence of organ dysfunction/ failure in intensive care units: Results of a multicenter, prospective study. Working group on "sepsis-related problems" of the European Society of Intensive Care Medicine. Crit Care Med 1998; 26:1793-1800.

21. Liano F, Pascual J. Epidemiology of acute renal failure: a prospective, multicenter, community-based study. Madrid Acute renal failure Study Group. Kidney Int 1996; 50:811-818.

22. Williams DI, Williams DJ, Williams IG, Unwin RJ, Griffiths MH, Miller RF. Presentation, pathology, and outcome of HIV associated renal disease in a specialist centre for HIV/AIDS. Sex Transm Infect 1998; 74:179-184.

23. Choi A, Scherzer R, Bacchetti P, Tien PC, Saag MS, Gibert CL, et al. Cystatin C, albuminuria, and 5-year allcause mortality in HIV-infected persons. Am J Kidney Dis 2010; 56:872-882.

24. Silva Junior GB, Daher EF, Mota RM, Menezes FA. Risk factors for death among critically ill patients with acute renal failure. Sao Paulo Med J 2006; 124:257-263. 